disease was great exhaustion; and, during the progress of the disease, this, with great nervous excitability, was infinitely more marked than any other symptom.

:3. The lessened proportion of dulness to the extent of the mischief, showing that the importance depended upon a conditiou other than mere deposition of solid matter.

t. The great absence of air after death, and the ease with which that which remained could be pressed out. This latter fact, with the post inortem appearance, clearly indicates that the essence of the disease was a process of collapse and destruction, and not mere filling up of the air-cells.

5. An inflammatory condition, of a low type, was a marked feature in the post mortem changes, although not very evident during life.

fi. Dr. Smith was of opinion that the so called tubercle, in itc: earliest stage, could not be distinguished from the epithelinin of the sir-vesicles; and the chief contents of the partially filled cells were more or less destroyed-these cells, free granules and granular cells, very like to pus-cells. He was also of opinion that this case of acute phthisis proved that, of all the parts of the lungs, the air-cells only were universally and essentially implicated, and that the condition of the bronchi was comparatively unimportant.

[To be continued.]

\section{Quriginal Commarmications.}

\section{O V A R I O T̃ O II Y.}

By Seprimes Gibron, A.B. and M.B.Cantab, Assistant-Physician to the London Hospital; late Physician to the

Metropolitan Free Hospital, etc.

Dunisg the last thirty years many practitioners in the treatment of ovarian dropsy have not acquiesced in the opinion expressed by Dr. William Hunter, "that the patient will have the best chance of living iongest under the disease who does the least to get ril of it"; but after the repeated failure of all other means of affording relief have boldly ventured to remove the entire eyst. In the absence of full and trustworthy statistics it is difficult to estimate the exact amount of succes which has attended this operation. In order to approximate to the truth, I will briefly state the result of the 162 operations, the analssis of which lias been published in vol. xxxry of the Medico-Chirurgical Transactions, by Dr. Robert Lee. I havo carefully perused the original records of these cases, and find-

1. That the abdomen was lail open in seven instances in which no ovarian disease existed; of these patients, one died and six recovered.

2. That the abdomen was laid open in fifty instances, in which it was found impracticable to remove the bulk of the diseased structures. Of these patients, thirty-five recovered (three bing cured by inflammation excited in the cyst), and tifteen died.

3 . In 105 cases the crst was almost entirely removed. Of these there died forty-one, and were cured sixty-four.

In other words, exclnding the seven cases in which no dis ease existed, we find that out of 155 operations there resulted 67 cures, 66 ; deaths, and 32 cases left unrelięved; i.e., a mortality of 42.58 per cent.

The most weighty objections that have been urged against this operation are-1, the great mortality; 2, the possibility of prolonging life considerably by other means; 3, the extreme difficulty of diagnosis, so as to be sure that the case is one which will offer no obstacles to the removal of the tumour.

To these objections, the following answers may be given

i. A mortality nearly, if not quite, as great is not considered a fatal oljection to other operations. As to amputation of the thigh, Mr. Syme observes-"The stern evidence of hospital statistics shows that the average frequency of death is not less than from 60 to 70 per cent." Of 987 cases collected by $\mathbf{M r}$. Phillips, 435 proved fatal, or 44 per cent. Mr. Curling states : "On referring to a table of amputations in the hospitals of London, performed from $183 \pi$ to 1843 , I find 134 cases of amputation of the thigh and leg, of which 55 were futal, giving a mortality of 41 per cent." The result of amputation of the hip-joint is still more unfavourable. Out of 81 cases, 26 were successful, and 58 unsuccessful. Hence the mortality from ovariotomy is not higher than that of other operations which are admitted to be justifiable.
2. With regard to the prolongation of life by palliative treat. ment and repeated tapping, it is not easy to estimate the exact gain. There are but few statistics to show the results of tapping. Mr. Southam, out of twenty cases, found that "fourteen patients died within nine months of the first operation, four of whom survived it only a few days. Of the remaining six, two died in eighteen months, and four lived for periods varying from four to nearly nine years. It further appears that paracentesis does not prolong life on an average for more than eighteen months and nineteen days, and that one in four dies from the effect of the first operation." These numbers are far too small to enable us to estimate the value of the operation; but, as far as they go, they do not adrocate very strongly the operation of tapping.

3. Grave errors have been committed ; so that we may rea sonably infer that the diagnosis is difficult and obscure. Other capital operations, the lenitimacy of which has never been called in question, have been performed under similar or greater errors of diagnosis. Sound limbs have been amputated, and healthy joints have been laid open; so that unless it be proved that in every case we are in doubt as to the exact nature, situation, adhesions, or the very existence of a tumour this argument cannot be held to be decisive against the operation.

During the last few years the labours of pathologists have rendered our knowledge of abdominal tumours more exact; and a glance at Dr. Robert Lee's tables will, I think, convince all who have had much clinical experience of ovarian disease, that the errors of diagnosis there detailed might, with our present knowledge, and a moderate amount of caution, have been avoided.

On this account the results of the operation are unsatis factory; and I for one am of opinion that, before condemning the operation, which is often our only means of arresting a fatal disease, we ought to give it a fairer and more extended trial. In order to contribute one such experiment to the large number that are required, I am induced to submit the following case to the consideration of the profession.

CASE. Margaret Wilford, aged 33, suffering from ovarian dropsy in an advanced stage, placed herself under the care of my late collengue, MIr. G. B. Childs, and had frequently expressed her willingness to undergo an operation for the entire removal of the disease. That a careful examination of the case might be made, and the opinion of other practitioners as to the propriety of the operation might be taken, she was admitted into the Metropolitan Free Hospital on March 23rd, 1853. At the request of Mr. Childs, to whose kindness I am indebted for the details of the operation, I examined the case, and agreed, in the event of the operation being performed, to undertake the medical treatment of the case.

She was a short, healthy-looking woman, of a florid coun tenance, cheerful expression, and dark complexion, with grey eyes. She appeared to be larger than at the full term of pregnancy. She had a peculiar husky voice; and, on examina tion, the internal fauces were found to be of a dusky red colour; there were several indentations and scars about the right tonsil, and the uvula was entirely gone. Her tongue was clean and moist, though marked with numerous transverse fissures on its surface. Her pulse was 76 , of small volume, and easily compressed. The bowels were regular; appetite good, without thirst. She usually slept quite soundly for about an hour at a time, when she used to awake suddenly with a start, caused, as she thought, by the weight of the tumour. The abdomen was uniformly distended, measuring in circumference at the umbilicus thirty-nine inches. There was slight tenderness and increased temperature of surface on the right side of the abdomen. In the right iliac and latera regions there was resonance on percussion, but on left side complete dullness. Fluctuation was distinetly felt over the abdorninal surface. There was no hardness or resistance to the hand felt on deep pressure in any part of the abdomen nor was there thickening or want of elasticity in the abdominal parietes, which appeared to be moveable without causing pain or crepitus.

An examination through the vagina showed that the ragina was large and relaxed, and that the uterus situated high up, had its cervix drawn to the left side, with the os inclining upwards. There was a considerable space intervening between the anterior wall of the vagina and cervix, whose convex surface was soft and elastic to the touch. The finger, however, resting on this surface, did not detect a sense of fluctuation when various parts of the abdomen were struck by the other hand. She stated that, with the exception of occasional 
gnawing and shooting pains in the belly, she enjoyed perfect health.

The history she gave of herself was as follows:-Menstruation commenced when she was fourteen years of age without any constitutional disturbance, and had continued to occur regularly up to the time of her admission. The flow generally lasted three or four days, and was always accompanied by gnawing pain, referred to the sacrum, and by sick headache, to which she was liable at other times. She had always had habitual but scanty leucorrhœa. Before her marriage, which took place nine years ago, she had been a prostitute for five or six years. About fifteen years ago she was under treatment in St. Thomas's Hospital for primary syphilis. She took mercury so as to produce salivation, and had severe ulceration of the throat. From that time to the present has never felt thoroughly well, suffering from frequent sore throat and dyspeptic symptoms, but has had no cutaneous eruption, nocturnal pains, or other secondary syphilitic symptoms. Fourteen years ago she was delivered of a dead eight-months child, and after an interval of five years she gave birth to another dead child at the seventh month of pregnancy.

Her attention was drawn ten months ago to a hard swelling in the left groin; and although she continued to menstruate regularly, she supposed that she was in the family-way. She consulted a medical man, who confirmed this supposition. The tumour progressively enlarged without causing her the least anxiety or distress until about four months ago, when she suddenly became so ill as to be obliged to take to her bed for a month.

She had acute pain in abdomen, constipated bowels, loss of appetite and sleep, great thirst; tenderness over the belly was such that she could not bear the weight of the bedclothes. Could only assume the sitting posture on account of the pain, which, though never entirely absent, seems to have occurred in paroxysms. After this attack the swelling increased rapidly, and she has never been entirely rid of the abdominal pain. Soon after this illness the catamenia were very abundant, lasting four or five weeks, but the discharge is stated to have been of a much paler colour than natural.

This history and the foregoing examination did not incline me to look upon the case as a very favourable one for the operation, for the following reasons; first, The fact of the patient having had unmistakable symptoms of peritonitis four months previously led me to suppose that there would bo found firm adhesions; secondly, The impetus of fluctuation could not be distinctly conveyed from the abdominal surface to the finger on the roof of the vagina; and I inferred that the cyst was multilocular; consequently it would be difficult or impossible to remove it by the small incision.

These objections, as well as the exceedingly dangerous nature of the operation, I took some trouble to explain to the patient; but, being a wornan of great nerve and singular fortitude, she still persisted in her request to have the cyst en tirely removed. Several experienced surgeons and obstetric physicians who examined the case gave it as their opinion that it was an appropriate one for the operation. Accordingly $\mathrm{Mr}$. Childs made up his mind to perform it.

On the night previous to the operation she was ordered ten grains of ox gall, with the view of getting the bowels freely acted on; she was also ordered a warm bath, in order to cleanse the pores of the skin, and thereby ensure a free perspiration after the operation. A flannel waistcoat and a pair of flannel drawers were provided for the patient. On the morning of the operation a dose of castor oil was administered, followed by an enema; a warm pediluvium was also used, and bottles of warm water were prepared for the feet. 'The air of the room was raised to the temperature of $65^{\circ}$ Fahr. and steamed; the windows were pasted over with brown paper, and the doorway covered with a stout blanket. The patient's feet and legs were covered with warm lambswool stockings; no food was allowed to be taken for some hours before the operation; and to avoid sickness she was instructed to suck ice.

For the following details of the operation I am indebted to Mr. Childs.

"March 28th. At 2 P.M. she was placed on a table about four feet high, her feet resting on a stool. My friend and late colleague, Dr. Septimus Gibbon, slowly and cautiously admin. istered chloroform, which very soon produced its effect. I commenced my incision about one inch below the umbilicus, extending it three inches downwards in the course of the linea alva. The sheath of the rectus muscle having been exposed, it was carefully opened on a director, and the peritoneum treated in the same way. The hand, previously dipped in water at a temperature of $98^{\circ} \mathrm{Fahr}$., was now introducer through the wound, and passed freely over the surface of the tumour, with the exception of its left side, where some slight adhesions were detected; but these readily gave way to the pressure of the hand. The cyst was seized with a tenaculum and tapped with a large sized trocar; and a house-pailful of dark brown fluid was drawn off. Another large cyst was punctured with a scalpel; and a large quantity of clear viscid fluid was allowed to escape. The cyst was now gradually drawn through the incision, with a view to reach the pedicle Some trifling adhesions were discovered also on the richt side, which were easily broken down. The pedicle being exposed a large curved needle, armed with a donble ligature of common twine, was passed through it between the ovary and the presumed position of the fimbriated extremity of the Fallopian tube. The ligature was ticl, and the tumour was removed with one sweep of the scaipel. It was not found requisite to secure any vessels during or after the operation. Ny friend Mr. I. B. Brown, who kindly lent me his assistance on this occasion, having previously dipped his hands in warm water, supported and replaced the bowels and omentum. The edges of the wound were brought tocrether, and three deep sutures entering about an inch from the edge of the wound, and passing out close to the divided edge of the peritoneum, penetrated the sheath of the rectus muscle. Three smaller sutures, including the integuments only, were placed between ench of tho former. The wound was dressed with a plugget of lint aipped in cold water, over which were placed three broad strips of adhesive plaister, and the whole of the abdomen covered with a flannel belt made for the purpose. The patient was placed on her bed with her knees semitlexed and tied together, a pillow supporting the hams. She was warmly covered, and a water cushion placed under her pelvis."

Half-an-hour after the operation her skin was warm ani moist; pulse 86, of good volume, and easily compressed. She complained of great pain in her back, but was in other respect. feeling comfortable. I ordered her to continue to suck ice, and to take no food except a little cold milk.

Sumat opii solidi gr. ij statim, et /postea gr. i secundis horis tantisper dum dolor vel insomnia urgeat.

8 P.M. I saw her with Mr. Childs, when her countenance was pale, but composed. The pupils of the eyes were a little contracted. The skin was hot and diy; the puise 120, of moderate volume, and soft. 'There was no distension of the abdomen. She complained of pain in her back aud legs, and of feeling thirsty, but was cheerful. She had taken three grains of solid opium, but had had no sleep. Two grains were ordered to be taken at once, and a grain every hour until she was free from pain or asleep.

March 29th, 9 A.s. The nurse informed me that soon after my visit last evening she ceased to complain of pain, and dosed until two o'clock this morning, when she slept soundly until 8 A.M.

Her countenance this morning was not indicative of suffering. The skin was warm and moist; pulse 120 , of molerate volume, and compressible. The tongue had a dry brownish red streak down its centre, but was moist and thinly furred a its edges. She had passed a little wrine with much pain and difficulty; about a pint more, clear and of natural colour, was drawn off by the catheter. The abdomen was not distended. There was considerable tenderness on the right iliac region. She complained of a feeling of soreness in this place. She had some degree of thirst, and no appetite. She was perfectly free from pain, and quite cheerful. She had a cup of cold tea for breakfast. She was ordered to omit taking the opiurn; to have mercurial ointment rubbed into her axilla; to drink barley water and milk; and to continue to suck ice.

4 P.M. I met Mr. Borlase Childs in consultation. The patient complained that her cough troubled her. She expectorated a little mucus. Her countenance was cheerful; the skin warm and moist; the pulse 124, of moderate volume, and soft; the tongue was moist and thinly covered with a white fur. There was no distension nor complaint of soreness of the belly. The tenderness was greatest just to the right of the wound. About half a pint of deep coloured, though clear, urine was drawn off. She was ordered to resume taking a grain of solid opium every four hours; to have the strong mercurial ointment rubbed in; and at 6 p.ir. to take a little beef-tea.

At 9 P.M. I was sent for, and found her much distressed by a collection of mucus in the bronchial tubes, all attempts to raise it causing great pain in the abdomen. Loud mucous râles were heard over the chest during inspiration and expira tion. The countenance was tranquil; there was no marked 
lividity of the lips. The skin was moist and warm; the pulse 100 , of moderate volume, but readily compressed. The tongue was moist, and thinly furred. The belly was not more distended or tender. She was directed to have an ounce of wine immediately, and half an ounce every four hours, and to take beef-tea.

Bo Spiritûs ammonix aromat. $m \times x$; tincturæ camphoræ comp. $j^{i}$; liquoris opii sedativi $m \mathrm{x}$; misturæ camphoræ $3 \mathrm{vi}$. Fiat haustus 4 tis horis sumendus.

March 30 th. She slept a little during the first part of the night; but at 2 A.n. she was seized with vomiting of so distressing and urgent a character, that the matron sent for me st six o'clock. I found the patient retching violently; the matter that had been ejected was a dark fluid, which had the smell and appearance of beef-tea and wine. The countenance was pale, but not expressive of suffering; the skin was warm and moist; the pulse 120 , of moderate volume, and rather incompressible; the tongue moist, and covered with a thin fur. The abdomen was not distended, and was free from marked tenderness, although she complained of soreness, caused by vomiting and retching. Before the vomiting commenced she experienced difficulty and pain in raising the mucous secretion of the lungs, but did not assign this or the medicine as the canse of the vomiting. She was ordered to take a grain of solid opium, and a dranght of tartrate of soda, with three minims of dilute hydrocyanic acid, immediately; and to repeat the draucht in two hours if the vomiting continued.

$\because$ P.s. 'The vomiting was at once allayed by the draught. She was now perfectly free from pain, although she felt some nausea. The tongue was moist and clean; pulse 120 , rather small and soft. The cough was troublesome, and caused pain in the neighbourhood of the incision; but there was no great tenderness on pressure.

$M$ arch 31 st. The catamenia appeared last evening, and she felt better since the flow commenced. She had vomited four times since last note was made; the cough was rather better. She complained only of pain attending the effort of coughing. 'The tongue was moist, and slightly coated; the pulse 110 . The expression of face was good. The respirations were 20 per minute. She was ordered to continue to take jelly and veal broth; also to have a glass of sherry wine.

April 1st. Last night the ratient complained of violent pain referred to the lower part of her body, which was relieved by taking two grains of solid opium; and afterwards she is reported to have passed a good night, sleeping for several hours. The countenance was composed; the skin hot and perspiring the pulse 114, of moderate volume, and compressible; the tongue moist, and thinly covered with a whitish fur. The bowels liad not been opened. Urine had passed freely, and was reported not to be high coloured. She had no inclination for food, but drank freely of toast and water, which the nurse thought allayed the vomiting yesterday. The abdomen was somewhat distended, tympanitic, and tender in the right iliac fossa. The wound was suppurating freely, and of healthy appearance. All the ligatures appeared to be very tense; the subcutaneous ones were removed. In the hope of removing the flatus, I ordered a small turpentine clyster, the administration of which caused her to faint, and afterwards to vomit. It returned in about a quarter of an hour, with a small quantity of fiecal matter; when the patient began to complain of severe excruciating pain in the lower part of the belly and back, which increased in intensity, so as to cause her to throw her legs about, and exclaim that her inside was on fire. I saw her about three hours afterwards, and found her skin hot, but soft; the pulse 124, moderate in volume, sharp, but not very compressible; the tongue dry and brownish down its centre, moist at elges. The abdomen was not more distended than in the morning; it was tympanitic, very tender over a space as large as a crown-piece in the right iliac fossa. The temperature of the abdominal surface was not perceptibly increased. Two grains of opium were given immediately; and one grain was ordered to be taken in three hours, if the pain were severe. She was directed to suck a little ice.

Four hours afterwards, at 11 P.M., I again visited the patient, and found her with a hot dry skin; a pulse 128 , small, sharp, and incompressible; and a dry tongue. She was under the influence of the opiate, and consequently complained but little of pain ; but there was great tenderness in the right iliac region, to which six leeches were ordered to be applied, and to be followed by a large linseed-meal poultice. A drachm of strong mercurial ointment was ordered to be rubbed into the axiila.

April and, 10 A.m. She passed a comfortable night. The leeches drew well, and there was a firm clot of blood on the poultice. The skin was warm and moist; the pulse 120 , moderate in volume, and rather firm. The tongue had a dry brown streak down the centre, but was moist at the edges. The abdomen was still distended and tympanitic, but there was no in creased heat or tenderness of the surface generally. The tenderness in the right iliac region was much diminished. There was a copious discharge of well formed pus from the wound. The countenance was placid. She complained of no pain, but of great thirst. The ligatures were removed, and water dressing was applied to the wonnd. She was ordered to have strong mercurial ointment rubbed into the axillæ, and to take only toast and water.

10 P.M. At 5 o'clock this evening, the pain, of a burning, shooting character, similar to what she had had the previous two days, returned in the lower part of her body; and she threw off her stomach a quantity of brown fluid. The skin was warm and moist; the pulse 114, of good volume, and rather firm. The abdomen had been less tender since a linseed-meal poultice was applied at six o'clock, which she said considerably relieved the pain. She had alarming dreams, and said that the pain awakened her. She was ordered to take a grain of solid opium immediately, and to repeat it in three hours if required; to have a linseed-meal poultice applied to the abdomen; and strong mercurial ointment rubbed into the axilla.

April 3rd. She was kept awake by pain during the fore part of the night, but had slept well since 2 a.m. Her counte nance was not expressive of pain. The skin was warm and moist; the pulse 104, of moderate volume, and soft; the tongue moist, thinly covered with a white fur. The abdomen was less distended; little or no tenderness was felt in the right iliac fossa. There was some induration of the abdominal parietes around the wound, and abundant pus exuded on pressure. She complained of flatulence, not thirst. She drank a little warm tea. She was ordered to have mutton broth, or a little very weak wine and water, to drink.

B Spiritus armoraciæ comp., tincturæ cardamomi comp., àa mxx; aquæ menthæ piperitæ $\xi^{s s .}$ M. Fiat haustus 4 tis horis sumendus.

A linseed-meal poultice was applied to the abdomen.

10 r.s. At 5 o'clock this evening, she again had a return of the burning, severe pain, at the bottom of her body. $\mathrm{Mr}$. Childs saw her, and directed her to take a little wine and beef tea, which, she stated, altered the seat, but not the character of the pain. Since then an attack of agonising pain had been at once relieved by the expulsion of wind from the rectumproof that these were colicky pains, dependent on fiatulence. Her countenance was composed; the slin hard and dry; the pulse 124, of moderate volume, sharp, but not firm; the tongue moist, red, and clean at the tip and edges. The abdomen was not so prominent; there was some tenderness below the wound. She had no marked thirst, no appetite. She com plained that her head throbbed since taking the wine. She was ordered to omit the wine and beef-tea, and to take nothing more than toast and water. The mixture was continued; and she was directed to have a grain of opium, if required.

April 4th. She felt great relief from the peppermint mix. ture. She had been free from pain, and slept well, without taking the opiate. The countenance was more cheerful and less pale; the skin natural ; pulse 100 , normal; the tongue was moist, thinly furred down the centre, clean at the tip and edges. There was very little tenderness or distension of the belly. There was copious discharge of pus from the orifice through which the ligature passed. The urine passed freely; the bowels were not moved; the catamenia had entirely ceased. She had no thirst nor pain, and felt hungry. She was ordered to have a cup pudding and mutton broth. The peppermint mixture was continued.

April 5th. She had a few severe paroxysms of pain the previous evening, and had not passed a comfortable night, in consequence of being troubled with tenesmus. After many trials, she had succeeded only in passing a very small quantity of fæcal matter. The skin was natural; the pulse 100 , of moderate volume, and soft; the tongue clean and moist. There was no distension or tenderness of the abdomen, worth men. tioning. Pus continued to flow freely from the wound. When the ligature was pulled, or when the abdomen was pressed, a few air-bubbles also escaped. The appetite continued good; she had no thirst

B. Liquoris cinchonæ flavæ $m v$; tincturæ cardamomi comp. mxv; aquæ menthæ piperita z̧i. M. Fiat haustus ter die sumendus. 
She was ordeced to have two ounees of wine, rice pudding, and mutton broth.

April 6th. The patient had not slept much during the night. She suffered from pain referred to the sacrum, and tenesmus, up to 4 A.r., when she passed a large solid healthy looking evacuation, and had been easier since.

11 A.u. I found her asleep. The countenance was natural ; the skin warm and moist; the pulse 108, of moderate volume, and compressible; the tongue clean and moist. Between two and three ounces of "laudable" pus, which had never had any ficcal odour, cxuded from the wound in the course of the twenty-four hours. Her appetite was good; she had no thirst. She was ordered to have plain suet pudding and mutton broth, and to omit the wine. The draught was continued; and she was ordered to take a grain of solid opium at bedtime, if required.

April 7 th. The bowels had been opened twice since yesterday morning. The patient slept soundly after taking the opiate. The skin was warm and moist; the pulse 108, of molerate volume, and soft. She was lying on her side, for the first time since the operation.

April 8th. With the exception of being troubled with flatulence, she continued to progress favourably. The discharge of pus from the wound was not quite so copious. Her appetite had greatly improved. She was put upon half diet, and ordered to have three ounces of sherry daily.

At 10 P.M., I was called to see her, in consequence of a profuse discharge taking place from the bowels, accompanied by Hatus. She was free from pain, and complained of no uneasiness or tenderness of the abdomen. I directed her to take a draught of chall mixture, with aromatic confection; and ten minims of laudanum every three hours, so long as the purging continued. The diarrboa ceased after one dose of the medicine. She continued to take her bark mixture and wine.

The ligature came away on April 14th, sixteen days after the operation. The wound had perfectly healed on the 21st, when she expressed herself as fieeling quite well.

April 25th. She was discharged from the Hospital. Up to the present time, I have seen her every year, and found that she has enjoyed excellent health, and that there has been no enlargement of the other ovary, or any derangement of the other abdominal organs.

\section{ON DISEASES OF JOINTS.}

By Holues Coote, Esq., F.R.C.S., Assistant-Surgeon to St. Bartholomew's Hospital, and to the Poyal Orthopædic Hospital, etc.

\section{IATERAL CURVATURE OF THE SPINE. \\ [Continued from page 165.]}

If the treatment of lateral curvature be involved, according to some authors, in mystery, the fault lies with those who set aside in this special subject the general principles of surgery. "The disease," says a modern author, "consists simply in relaxation of the muscles and ligaments of the spine, in consequence of which the vertebral column, being no longer able to support the weight of the head, neck and shoulders, becomes curved to one side." The condition of the vertebral column is, therefore, analogous to that of the bones of the leg in knockknee (genu valgum).

Suppose a surgeon were consulted by a young person suffering from knock-knee and flat-foot, would he recommend his patient to strap a knapsack on his back and take a walking tour through a hilly country? Assuredly not; he would advise rest; he would apply splints outside the leg, and supports to restore the lost arch of the foot.

But let the patient be a young girl with a curvature of the spine, and in a moment the current of the surgeon's thoughts is changed. He recommends tonic medicines, frictions of the muscles of the back, the use of dumb-bells, calisthenic exercises, weights on the top of the head! By those means he assures his patient, whom he knows to be suffering from weakness of ligaments, that the muscles of the back may be strengthened and that the increase of the deformity may be prevented.

I repeat that the muscles have no share in originating the deformity: the dissection, recorded in a former number of the Journal, of a foetus born with lateral curvature, proves this point. But when the spine is curved, the muscles in the concavity contract like the string to a bow, and if they could act, they would increase the deformity.
I will next direct attention to the following point. The de. formity, once established, increases at different rates of progress, if unchecked, through life. There is no age at which sufficient consolidation of the bones and ligaments occurs to secure the patient from increase of the evil.

CASE I. Rosa S., aged 11, residing near Cambridge, became the subject of a very slight lateral curvature during the year 1857. I saw her November 18 th, $185 \%$, in conjunction with a professional friend, and it was arranged, not without misgiving on my part, that in consequence of the small amount of deviation from the straight line, she should have only that support which would be afforded by a pelvic band and two crutches to extend to the axillæ. Proper directions were given that the patient, a tine tall girl, should take a sufficient amount of rest. I heard from the mother, on several occasions, that there was no marked improvement: then came intimation that the curvature was increasing, and I according arranged to see the child, February $24 \mathrm{th}$, in London. There was a well marked curve to the right, including the whole of the dorsal vertebræ; the lumbar vertebræ were upright, but it was easy to see that in a short time a compensating inferior curve would form. The health was good, except that there was general weakness after exercise, and the patient disliked the deformity especially as affecting the shoulder and hip. I directed a pad to be applied by means of a steel bar, worked with screws and pressing on the convexity of the curve, as is usually done at the Orthopædic Hospital. A steel crutch extended along the left side of the body to the corresponding axilla. Sufficient time has not elansed for me to pronounce that the patient is cured. But she is about to return to the country in comparative comfort the deformity will not increase, and she will be enabled to take exercise suited to her age in safety. In the course of a few months, she may be able to wear properly constructed stays.

Case Ir. A young girl, aged 18, named Sarah P., apprenticed to a draper, applied to me at the Royal Orthopædic Hospital, January 1858, in consequence of lateral curvature of the spine of two years duration. She had consulted many surgeons in the county whence she came, and had been dissuaded from wearing instrumental support. The curvature increased. She experienced general pain over the back, extending to both shoulders, especially the right; pain extended round the ribs, along the course of the intercostal nerves, producing " stitch in the side;" there was frequent palpitation of the heart and faintness towards night time. For the last six months, menstruation had ceased. Upon examination, I detected a single long curvature, including all the dorsal and the upper lumbar vertebræ, the convexity directed to the right. January 18th, 1858. I directed the application of the instrument usually employed, with a single pad.

February 14th. She appeared to be greatly relieved of all the pains which had been fixed in the back; she had gained a quarter of an inch in length.

February 21st. Menstruation has returned; her general health is much improved; she considers herself fit to return to her home, above one hundred miles from London, promising to present herself in the course of a few months.

CASE III. Maria M-, aged 16, has been the subject of lateral curvature for three years; she suffers from great weakness and pain in the side; her occupation is that of dress-making, and she sits thirteen hours a day. Upon examination, there was detected a double lateral curvature, namely, a short curve to the right in the upper dorsal region, and a long curve to the left, extending from the dorsal to the lumbar vertebræ. Ja nuary 18th, 1858. An instrument with a double pad was applied.

February 28th. The case under treatment. The pain and sense of weakness is greatly relieved.

CASE Iv. Harriett $\mathrm{B}-$, aged 26, domestic servant, occasionally has carried a child; has suffered from lateral curvature for the last three years. It has of late so much increased as to prevent her following her occupation. The symptom of which she complained most was pain under the inferior angle of the right scapula. Upon examination, it was found that she had a single curve to the right.

February 18th. An instrument, as usually constructed, with a single pad, was directed to be worn.

February 24th. The pain has subsided. The spinal curvature is becoming straight.

A young woman has been under my care, since October last, with double lateral curvature. An instrument has been applied, and she has gained at the present time one inch and three-quarters in height. I have given directions that she should return to the country, and see me again in a couple of 